\title{
Analysis of SiC MOSFETs under hard and soft-switching
}

Link to publication record in Manchester Research Explorer

\section{Citation for published version (APA):}

Ahmed, M. R., Todd, R., \& Forsyth, A. (2015). Analysis of SiC MOSFETs under hard and soft-switching. In Energy Conversion Congress and Exposition (ECCE), IEEE 2015 (pp. 2231-2238). IEEE.

\section{Published in:}

Energy Conversion Congress and Exposition (ECCE), IEEE 2015

\section{Citing this paper}

Please note that where the full-text provided on Manchester Research Explorer is the Author Accepted Manuscript or Proof version this may differ from the final Published version. If citing, it is advised that you check and use the publisher's definitive version.

\section{General rights}

Copyright and moral rights for the publications made accessible in the Research Explorer are retained by the authors and/or other copyright owners and it is a condition of accessing publications that users recognise and abide by the legal requirements associated with these rights.

\section{Takedown policy}

If you believe that this document breaches copyright please refer to the University of Manchester's Takedown Procedures [http://man.ac.uk/04Y6Bo] or contact uml.scholarlycommunications@manchester.ac.uk providing relevant details, so we can investigate your claim.

\section{OPEN ACCESS}


This paper was published at the IEEE Energy Conversion Congress and Exposition (ECCE) in Sept. 2015, doi 10.1109/ECCE.2015.7309974, and is available at:

http://ieeexplore.ieee.org/stamp/stamp.jsp?tp=\&arnumber=7309974

M. R. Ahmed, R. Todd and A. J. Forsyth, " Analysis of SiC MOSFETs under hard and soft-switching," IEEE Energy Conversion Congress and Exposition (ECCE), pp. 2231-2238, Sept. 2015, doi: 10.1109/ECCE.2015.7309974.

(C) 2015 IEEE. Personal use of this material is permitted. Permission from the IEEE must be obtained for all other uses, in any current or future media, including reprinting/republishing this material for advertising or promotional purposes, creating new collective works, for resale or redistribution to servers or lists, or reuse of any copyrighted component of this work in other works. 


\title{
Analysis of SiC MOSFETs under Hard and Soft- Switching
}

\author{
M. R. Ahmed, R. Todd and A. J. Forsyth \\ School of Electrical and Electronic Engineering, Power Conversion Group \\ The University of Manchester \\ Manchester, U.K. \\ md.rishad.ahmed@postgrad.manchester.ac.uk
}

\begin{abstract}
Analytical models for hard-switching and softswitching SiC MOSFETs and their experimental validation are described in this paper. The models include the high frequency parasitic components in the circuit and enable very fast, accurate simulation of the switching behaviour of $\mathrm{SiC}$ MOSFET using only datasheet parameters. The much higher switching speed of $\mathrm{SiC}$ devices over $\mathrm{Si}$ counterparts necessitates a clear detailed analysis. Each switching transient was divided into four distinct sub-periods and their respective equivalent circuits were solved to approximate the circuit state variables. Nonlinearities in the junction capacitances of $\mathrm{SiC}$ devices were considered in the model. Analytical modelling results were close to the LTspice simulation results with a threefold reduction in the simulation time. The effect of snubber capacitors on the soft-switching waveforms is also explained analytically and validated experimentally, which enables the analytical model to be used to evaluate future softswitching solutions. It was found that the snubber branch can significantly reduce the turn off ringing of the SiC MOSFET in addition to the reduction of switching losses.
\end{abstract}

Keywords-SiC MOSFET analytical model; switching transients; snubber capacitor; parasitic effect; soft-switching

\section{INTRODUCTION}

Silicon-based power switching devices are now approaching their performance limits due to the inherent material properties [1]. Silicon carbide (SiC) is a widebandgap semiconductor, which compared to silicon has superior physical and electrical properties especially at high temperature $[1,2]$. $\mathrm{SiC}$ power devices are considered to be one of the enabling technologies for future power dense DCDC converters, as they can be operated at very high switching frequencies which reduces the size of the magnetic components. The fast switching transitions of these devices do however create design issues for the converter, including parasitic current and voltage oscillations, electromagnetic interference (EMI) effects and control complexities. To gain the full benefit from a $\mathrm{SiC}$ power dense converter requires detailed understanding of these devices.

To understand the SiC MOSFET static and dynamic behaviour, several modelling approaches have been proposed, including semiconductor physics models $[3,4]$ and behavioural models [5-7]. Most of the models are complex

The authors thank the UK Engineering and Physical Sciences Research Council (EPSRC) for the funding of this project as part of the Centre for Power Electronics. or poorly incorporate the circuit parasitic components, and so produce inaccurate circuit waveforms. Analytical modelling of the switching transients can be a good approach to understand the switching behaviour of SiC MOSFETs. The models can then be extended to incorporate circuit parasitics and also soft-switching of the power devices. For example, [8] showed a simple circuit model for the off-state of a SiC MOSFET to predict the dv/dt-induced false turn on. However, the modelling of other switching transient states was not shown. One of the key objectives of this work is to develop an analytical model to evaluate SiC MOSFETs full switching behaviour.

Switching test results of $\mathrm{SiC}$ MOSFETs in converter circuits have shown that their switching losses can significantly limit the operating frequency [9, 10]. Soft switching techniques can be employed to minimise the switching losses and a soft-switched $\mathrm{SiC}$ boost converter $(12.5 \mathrm{~kW}, 112 \mathrm{kHz})$ was reported in [11] with an efficiency of around $98 \%$. However, the impact of the snubber branch on the switching waveforms needs to be investigated to fully evaluate the performance benefits, which is another capability of this analytical model.

\section{OVERVIEW OF SIC MOSFET SWITCHING}

\section{A. Hard-switching}

To investigate the hard-switching of a SiC MOSFET, the double-pulse test (DPT) circuit shown in Fig. 1(a) is used. Fig. 1 (b) shows the ideal circuit waveforms. Two pulses with variable widths are provided at the gate driver input as shown in Fig. 1 (a). The first pulse has a larger width which determines the current rise in the inductor, L shown in Fig. 1 (b). When the current reaches the desired level, the MOSFET (device under test, DUT) is turned off and the turn off transient waveforms can be observed. At this transient, the load current commutates to the Schottky diode from the MOSFET channel. During the off state of the MOSFET, the inductor current remains virtually constant. Then the smaller width pulse is applied to the gate driver and the turn on transient waveforms can be observed at the same current and voltage level of the turn off transient. Finally, when the smaller pulse finishes, the inductor current slowly decays in the closed loop it forms with the Schottky diode. 

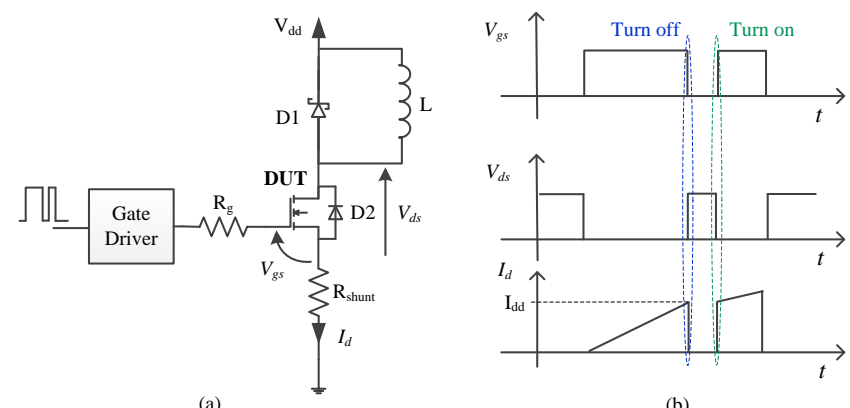

(a)

Fig. 1. (a) Double-pulse test (DPT) circuit, (b) Ideal circuit waveforms

Fig. 2(a) shows the equivalent DPT circuit for the active region of the MOSFET, when the main voltage and current transitions occur during turn on. Fig. 2(a) includes all the parasitic components associated with both the SiC MOSFET and other circuit components, such as the MOSFET common source inductance, $\mathrm{L}_{\mathrm{s}}$, drain lead inductance, $\mathrm{L}_{\mathrm{d}}$, gate lead inductance, $\mathrm{L}_{\mathrm{g}}$, parasitic capacitances of the MOSFET, diode and load inductor lumped parasitic capacitance, $\mathrm{C}_{\mathrm{ak}}$, and the equivalent series resistance of the power loop, $\mathrm{R}_{\mathrm{s}}$. Fig. 2(b) shows simplified transient waveforms for the MOSFET drain to source voltage, $V_{d s}$, drain current, $I_{d}$, gate to source voltage, $V_{g s}$, Schottky diode voltage, $V_{a k}$, and the diode current, $I_{f}$.
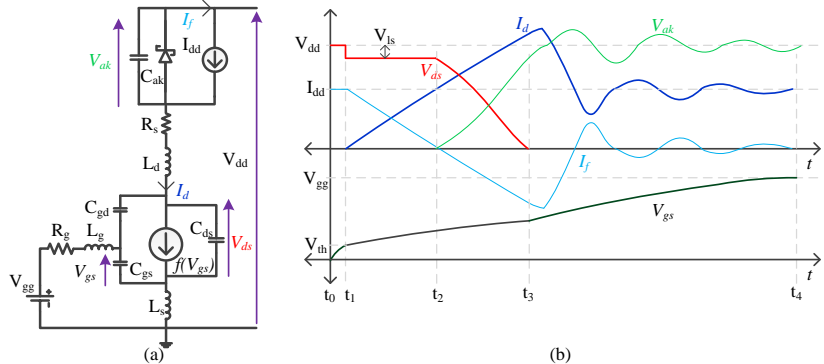

Fig. 2. (a) Equivalent circuit of DPT during the active region of $\mathrm{SiC}$ MOSFET, (b) DPT waveforms during turn on

The $V_{g s}$ increases during $\mathrm{t}_{0}-\mathrm{t}_{1}$ in an exponential manner as the gate current charges the MOSFET input capacitances, $\mathrm{C}_{\mathrm{gs}}$ and $\mathrm{C}_{\mathrm{gd}} . V_{g s}$ reaches the threshold level, $\mathrm{V}_{\mathrm{th}}$ at $\mathrm{t}_{1}$ and $I_{d}$ starts to increase. At the same time, diode current, $I_{f}$ also starts to fall from the load current, $\mathrm{I}_{\mathrm{dd}}$ level and at time $\mathrm{t}_{2}$, the current commutation between the diode and MOSFET finishes. During this sub-period, $\mathrm{t}_{1}-\mathrm{t}_{2}$, an almost constant voltage drop, $\mathrm{V}_{\mathrm{ls}}$, happens across, $\mathrm{L}_{\mathrm{d}}$ and $\mathrm{L}_{\mathrm{s}}$, which reduces $V_{d s}$ by $\mathrm{V}_{\mathrm{ls}}$ from the input DC link voltage, $\mathrm{V}_{\mathrm{dd}}$.

At time $\mathrm{t}_{2}, I_{d}$ reaches the load current level $\left(\mathrm{I}_{\mathrm{dd}}\right), V_{d s}$ starts to fall as the voltage starts to build up across the diode parasitic capacitor, $\mathrm{C}_{\mathrm{ak}}$. The charging current of the parasitic capacitor increases $I_{d}$ almost linearly until the diode voltage, $V_{a k}$ reaches the level $\mathrm{V}_{\mathrm{dd}}-\mathrm{V}_{\mathrm{ls}}$ at time $\mathrm{t}_{3}$. At this point, $V_{d s}$ reaches its on-state voltage level, $\mathrm{V}_{\mathrm{ds}(\mathrm{on})}$.

After $t_{3}, I_{d}$ starts to reduce as the energy in the stray inductance, $\mathrm{L}_{\mathrm{d}} \& \mathrm{~L}_{\mathrm{s}}$ transfers to the diode capacitor. The resonance between the diode parasitic capacitor, $\mathrm{C}_{\mathrm{ak}}$ and circuit stray inductance, $\mathrm{L}_{\mathrm{d}} \& \mathrm{~L}_{\mathrm{s}}$ continues until all the resonating energy is dissipated by the stray resistance, $R_{s}$, of the circuit. Finally, once the resonance period is complete, the drain current is equal to the load current, $\mathrm{I}_{\mathrm{dd}}$, the diode voltage, $V_{a k}$ becomes equal to the DC link voltage, $\mathrm{V}_{\mathrm{dd}}$, and the $V_{g s}$ is equal to the gate supply voltage, $\mathrm{V}_{\mathrm{gg}}$. The switching transient at turn off follows a reverse process to that seen at turn on. The sub-intervals for turn off are the same as those at turn on but occur in the reverse order.

\section{B. Soft-switching}

To facilitate the soft-switching test, a different arrangement of the DPT circuit shown in Fig. 3(a) was used. First, a single gate pulse is given to the upper device, Q1, so that the load current, $I_{L}$ increases in the inductor, $\mathrm{L}$, to the desired level, $\mathrm{I}_{\mathrm{dd}}$ (Fig. 3(b)). Turning off Q1 will turn on the body diode of Q2 and $I_{L}$ will start to decrease because of the reverse voltage across the inductor, L. After a deadtime, a second gate pulse, approximately double the width of the first pulse is applied to the lower device, Q2. This forces the load current to change direction and reach $-\mathrm{I}_{\mathrm{dd}}$. In both turn on and turn off transients the two snubber capacitors, $\mathrm{C}_{\mathrm{s} 1}$ and $\mathrm{C}_{\mathrm{s} 2}$, charge and discharge in a lossless manner to enable zero-voltage switching of both devices.

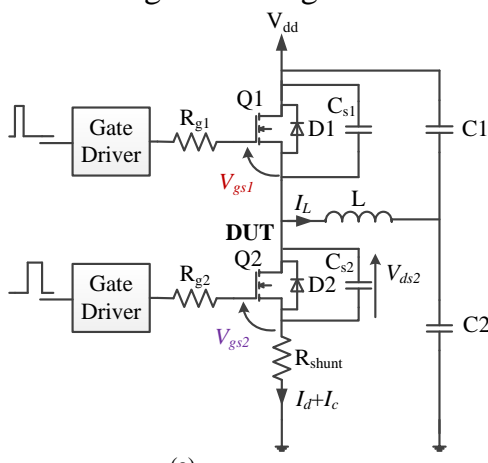

(a)

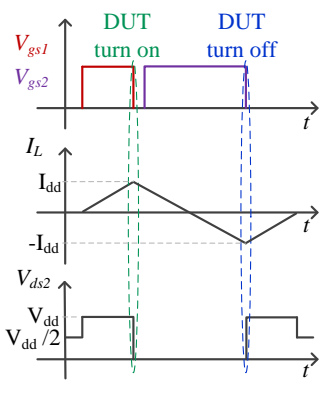

(b)
Fig. 3. (a) DPT for soft-switching operation (b) Ideal circuit waveforms

Fig. 4(a) shows the equivalent soft-switching DPT circuit at the active region of the DUT MOSFET during turn off. Here $\mathrm{C}_{\mathrm{s} 1}$ and $\mathrm{C}_{\mathrm{s} 2}$ are the two snubber capacitors and $I_{c l}$ and $I_{c 2}$ are the currents flowing through these capacitors respectively. $\mathrm{L}_{\mathrm{s} 2}$ is the parasitic inductance of $\mathrm{C}_{\mathrm{s} 2}$. The parasitic inductance of $\mathrm{C}_{\mathrm{s} 1}$ is neglected to simplify the analysis as explained later in Section III.B. Detailed turn off transient waveforms are shown in Fig 4 (b).
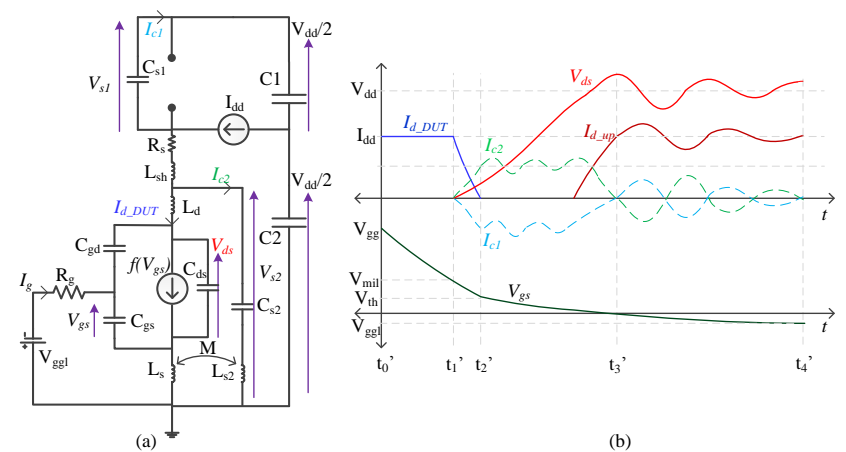

Fig. 4. (a) Equivalent circuit of soft-switching DPT during the active region of SiC MOSFET, (b) DPT waveforms during turn off

The gate to source voltage, $V_{g s}$ decreases during $\mathrm{t}_{0}$ ' $-\mathrm{t}_{1}$ ' in an exponential manner as the gate current discharges the 
MOSFET input capacitances, $\mathrm{C}_{\mathrm{gs}}$ and $\mathrm{C}_{\mathrm{gd}} . V_{g s}$ reaches the miller level, $\mathrm{V}_{\text {mil }}$ at $\mathrm{t}_{1}$ ' and $V_{d s}$ starts to increase and $I_{d}$ starts to decrease. Due to the snubber capacitor, $\mathrm{C}_{\mathrm{s} 2}, V_{d s}$ increases very slowly while $I_{d}$ falls to zero at $\mathrm{t}_{2}$ ' and $V_{g s}$ reaches its threshold level, $\mathrm{V}_{\text {th. }}$. In this sub-period $\mathrm{I}_{\mathrm{dd}}$ commutates to the two snubber capacitors.

During the sub-period $t_{2}{ }^{\prime}-t_{3}, I_{d d}$ is shared equally by the two snubber branches. Due to the parasitic inductance in the current paths, both $I_{c l}$ and $I_{c 2}$ will be oscillatory. Towards the end of the $\mathrm{t}_{2}$ '- $\mathrm{t}_{3}$ ' sub-period $V_{d s}$ will reach $\mathrm{V}_{\mathrm{dd}}$ and the upper device will start to conduct $\left(I_{d_{-} u p}\right)$ terminating the snubber branch currents. After $t_{3}$, the circuit capacitance and inductances will continue to resonate until a steady state is reached when the upper device current, $I_{d_{-} u p}$ equals the load current, $\mathrm{I}_{\mathrm{dd}}, I_{c 1}$ and $I_{c 2}$ becomes zero, and $V_{g s}$ equals $\mathrm{V}_{\mathrm{ggl}}$.

\section{MODELLING OF SIC MOSFET SWITCHING TRANSIENTS}

Analytical modelling of SiC MOSFET turn on and turn off transients requires the solution of four equivalent circuits corresponding to the four distinct stages of both transients. The modelling approach is similar to the published $\mathrm{Si}$ MOSFET analytical models [12, 13], but the difference is the incorporation of the major circuit parasitic components in all of the transient stages. Also no assumptions are used in the model to predict voltage transitions in the equivalent circuits. 'ode45' differential equation solver was used in MATLAB to solve the state equations of each sub-period of the analytical models. For each sub-period, the state variables were solved, and the final values were the initial condition for the next sub-period.

\section{A. Hard switching}

The equivalent circuits for turn on and turn off transient states are shown in Fig. 5 (derived from the DPT circuit in Fig. 1(a)). Here, $L_{d}$ is the sum of inductances of the MOSFET drain lead, $\mathrm{L}_{\text {drain, }}$ PCB current paths, $\mathrm{L}_{\mathrm{pcb}}$, diode leads, $\mathrm{L}_{\text {lead, }}$ and current shunt resistor, $\mathrm{L}_{\text {shunt. Four state }}$ variables, $V_{g s}, V_{d s}, I_{d}$ and $\dot{I}_{d}$ (rate of change of drain current), were considered and are solved using four state space equations. A step gate pulse from $\mathrm{V}_{\mathrm{ggl}}$ to $\mathrm{V}_{\mathrm{gg}}$ is used to initiate the turn on transient. The other two inputs are supply voltage, $\mathrm{V}_{\mathrm{dd}}$ and load current, $\mathrm{I}_{\mathrm{dd}}$. The four sub-periods during the turn on transient correspond to (i) turn on delay, (ii) drain current rise, (iii) drain to source voltage fall and (iv) ringing stages. The gate inductance, $\mathrm{Lg}_{\mathrm{g}}$ was neglected in the proposed model assuming gate current, $I_{g}$, is much smaller than the drain current, $I_{d}$, and the validity of this assumption was confirmed by the experimental measurements in Section IV.

\section{Turn on transient model}

A step gate pulse from $V_{g g l}$ to $V_{g g}$ initiates turn on which drives the solution of the turn on transient model $\left(\mathrm{V}_{\mathrm{ggl}}<0\right)$.

\section{Sub-period 1: $\left(t_{0^{-}} t_{1}\right)$ (turn on delay, $\left.t_{d(o n)}\right)$}

After the gate pulse is applied, the gate current charges the MOSFET input capacitors $\mathrm{C}_{\mathrm{gs}}$ and $\mathrm{C}_{\mathrm{gd}}$. The MOSFET stays off until $V_{g s}$ reaches $\mathrm{V}_{\text {th }}$ and the load current, $\mathrm{I}_{\mathrm{dd}}$ circulates through the Schottky diode. The drain current is zero and the drain to source voltage is equal to the DC link voltage, $\mathrm{V}_{\mathrm{dd}}$ in this sub-period. Therefore, the only state variable to be solved in this sub-period is $V_{g s}$. After solving equations (1)-(3) using $\mathrm{V}_{\mathrm{g} \_ \text {in }}=\mathrm{V}_{\mathrm{gg}}$ and the initial condition, $V_{g s}(0)=\mathrm{V}_{\mathrm{ggl}}$, an expression for gate to source voltage, $V_{g s}$ can be found (4)

$$
\begin{aligned}
& \mathrm{R}_{\mathrm{g}} I_{g}(t)=\mathrm{V}_{\mathrm{g}_{-} \mathrm{in}}-V_{g s}(t)-\mathrm{L}_{\mathrm{s}} \frac{d I_{d}(t)}{d t} \\
& I_{g}(t)=\mathrm{C}_{\mathrm{gs}} \frac{d V_{g s}(t)}{d t}+\mathrm{C}_{\mathrm{gd}} \frac{d V_{g d}(t)}{d t} \\
& V_{g s}(t)=V_{g d}(t)+V_{d s}(t) \\
& V_{g s}(t)=\mathrm{V}_{\mathrm{gg}}+\left(\mathrm{V}_{\mathrm{ggl}}-\mathrm{V}_{\mathrm{gg}}\right)\left[\exp \left(-\frac{t}{\mathrm{R}_{\mathrm{g}} \mathrm{C}_{\mathrm{iss}}}\right)\right]
\end{aligned}
$$

where, $I_{d}(t)=\mathrm{I}_{\mathrm{DD}}$ and $\mathrm{C}_{\mathrm{iss}}=\mathrm{C}_{\mathrm{gs}}+\mathrm{C}_{\mathrm{gd}}$. The turn on delay, $t_{l}-t_{0},(5)$, is the time required for $V_{g s}$ to reach $\mathrm{V}_{\text {th }}$ from $\mathrm{V}_{\mathrm{ggl}}$.

$$
t_{1}-t_{0}=-\mathrm{R}_{\mathrm{g}} \mathrm{C}_{\mathrm{iss}} \ln \left(\frac{\mathrm{V}_{\mathrm{gg}}-\mathrm{V}_{\mathrm{th}}}{\mathrm{V}_{\mathrm{gg}}-\mathrm{V}_{\mathrm{ggl}}}\right)
$$

Sub-period 2: $\left(t_{1}-t_{2}\right)$ (current rise time, $t_{\text {ir }}$ )

Current commutation between the diode and MOSFET happens in this stage. As the MOSFET works in the saturation region its channel current will be directly proportional to $V_{g s}$. $V_{d s}$ decreases in this stage because of the di/dt induced voltages across $\mathrm{L}_{\mathrm{s}}$ and $\mathrm{L}_{\mathrm{d}}$ as shown in (6).
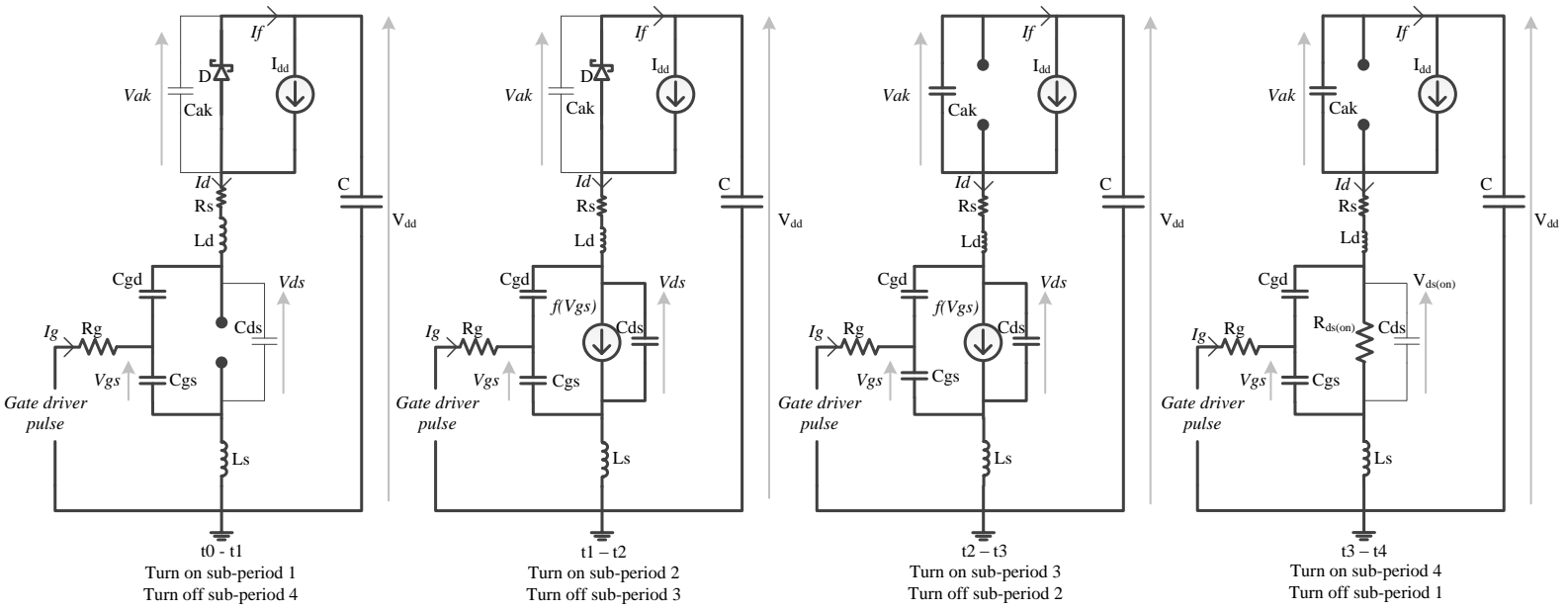

Fig. 5. Equivalent circuits for turn on and turn off sub-periods corresponding to the hard-switching DPT circuit 


$$
V_{d s}(t)=\mathrm{V}_{\mathrm{dd}}-\left(\mathrm{L}_{\mathrm{s}}+\mathrm{L}_{\mathrm{d}}\right) \frac{d I_{d}(t)}{d t}-\mathrm{R}_{\mathrm{s}} I_{d}(t)
$$

The drain current can be found by adding the channel current to the MOSFET output capacitor discharge current as shown in (7) where $\mathrm{C}_{\mathrm{oss}}=\mathrm{C}_{\mathrm{ds}}+\mathrm{C}_{\mathrm{gd}}$.

$$
I_{d}(t)=g_{\mathrm{m}}\left[V_{g s}(t)-V_{\mathrm{th}}\right]+\mathrm{C}_{\mathrm{oss}} \frac{d V_{d s}(t)}{d t}
$$

The state equations (A1) for this sub-period are derived using (1)-(3) and (6)-(7) and are shown in the Appendix. The current rise time, $t_{2}-t_{1}$ is the time required for $V_{g s}$ to reach $V_{\text {mil }}$ from $V_{t h}$, where, $V_{\text {mil }}=\frac{I_{d d}}{g_{m}}+V_{\text {th }}$ and $g_{m}$ is the transconductance of the MOSFET. The drain current will reach the load current level by the end of this sub-period.

\section{Sub-period 3: $\left(t_{2}-t_{3}\right)$ (Voltage fall time, $\left.t_{v f}\right)$}

The voltage across the Schottky diode capacitor, $V_{a k}$ is expressed as (8) and $V_{d s}$ can be expressed as (9) for this subperiod. The state equations (A2) for this sub-period are derived using (1)-(3), (7) and (8)-(9) and are shown in the Appendix.

$$
\begin{aligned}
& \frac{d V_{a k}(t)}{d t}=\frac{1}{\mathrm{C}_{\mathrm{ak}}}\left(I_{d}(t)-\mathrm{I}_{\mathrm{dd}}\right) \\
& V_{d s}(t)=\mathrm{V}_{\mathrm{dd}}-\left(\mathrm{L}_{\mathrm{s}}+\mathrm{L}_{\mathrm{d}}\right) \frac{d I_{d}(t)}{d t}-V_{a k}(t)-\mathrm{R}_{\mathrm{s}} I_{d}(t)
\end{aligned}
$$

The voltage fall time, $t_{3}-t_{2}$ is the time required for $V_{d s}$ to reach $\mathrm{V}_{\mathrm{ds}(\mathrm{on})}$ from $V_{d s}\left(t_{2}\right)$.

\section{Sub-period 4: $\left(t_{3}-t_{4}\right)$ (Ringing period)}

As the MOSFET stays in the ohmic region, $V_{d s}$ can be considered constant, $\mathrm{V}_{\mathrm{ds}(\mathrm{on})}$. The state equations (A3) for this sub-period are derived using (1)-(3), (8) and (9) and are shown in the Appendix. The time for this sub-period, $t_{4}-t_{3}$ is approximated by the time required for $V_{g s}$ to reach $\mathrm{V}_{\mathrm{gg}}$ from $V_{g s}\left(t_{3}\right)$.

\section{Model implementation}

Fig. 6 shows a summary of the turn on transient model implementation process in MATLAB. The state equations are solved using the parameters and parasitic values of the DPT circuit shown in Table I (Section III.C). When solving (A2) for sub-period 3, the nonlinearities in junction capacitances were considered. These nonlinear voltage dependent parasitic capacitances of the MOSFET $\left(\mathrm{C}_{\mathrm{gd}}, \mathrm{C}_{\mathrm{iss}}\right.$ and $\left.\mathrm{C}_{\mathrm{oss}}\right)$ and the Schottky diodes $\left(\mathrm{C}_{\mathrm{ak}}\right)$ were modelled by fitting their datasheet curves to (10) which is based on the equation for low voltage silicon MOSFETs [12]. $\mathrm{C}_{0 \mathrm{v}}$ and $\mathrm{C}_{\mathrm{hv}}$ are the low voltage and high voltage capacitance values used to calculate the curve fitting coefficients $x$ and $C_{j}$. The $C_{h v}$ term has to be included to the equation to fit the variable capacitance curve for the wider voltage range of the $1200 \mathrm{~V}$ rated $\mathrm{SiC}$ MOSFETs.

$$
C=\frac{1}{\frac{1}{\mathrm{C}_{0 \mathrm{v}}}+\frac{V^{\mathrm{x}}}{\mathrm{C}_{\mathrm{j}}}}+\mathrm{c}_{\mathrm{hv}}
$$

The linear state equations (A2) were solved in a loop with different junction capacitance values updating after

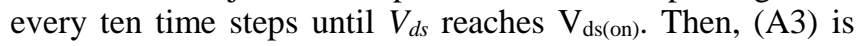

solved for sub-period 4, using low voltage junction capacitance values, until $V_{g s}$ reaches $\mathrm{V}_{\mathrm{gg}}$ when the simulation finally ends.

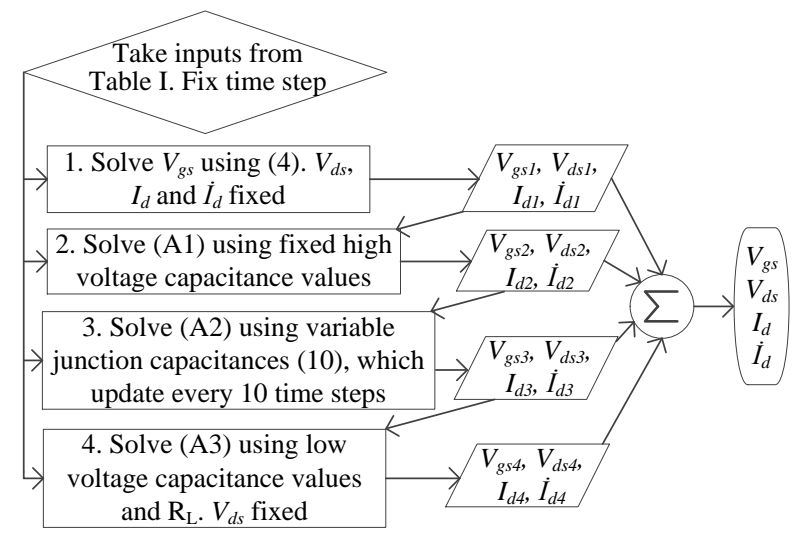

Fig. 6. Flow chart of turn on transient implementation

\section{Turn off transient model}

A step gate pulse from $\mathrm{V}_{\mathrm{gg}}$ to $\mathrm{V}_{\mathrm{ggl}}$ initiates turn off which drives the solution of the turn off transient model. The four turn-off transient sub-periods in Fig. 5 are essentially a mirror image of the turn-on transient sub-periods, and so, the state equations can be derived in a similar manner.

Sub-period 1: $\left(t_{4}-t_{5}\right)$ (turn off delay, $\left.t_{d(\text { off })}\right)$

After the negative gate pulse is applied, the MOSFET input capacitors $\mathrm{C}_{\mathrm{gs}}$ and $\mathrm{C}_{\mathrm{gd}}$ begin to discharge. The MOSFET stays in the ohmic region until $V_{g s}$ reaches $\mathrm{V}_{\text {mil }}$. The load current, $I_{d d}$ goes through the MOSFET channel, so, $V_{d s}$ can be considered constant, $\mathrm{V}_{\mathrm{ds}(\mathrm{on})}$. After solving (1)-(3) using $\mathrm{V}_{\mathrm{g} \_ \text {in }}=\mathrm{V}_{\mathrm{ggl}}$ and the initial condition, $V_{g s}(0)=\mathrm{V}_{\mathrm{gg}}$, the gate to source voltage can be found (11).

$$
V_{g s}(t)=V_{g g l}+\left(V_{g g}-V_{g g l}\right)\left[\exp \left(-\frac{t}{\mathrm{R}_{\mathrm{g}} \mathrm{C}_{\mathrm{iss}}}\right)\right]
$$

Turn off delay, $t_{5}-t_{4}$ is the time required for $V_{g s}$ to reach $\mathrm{V}_{\text {mil }}$ from $\mathrm{V}_{\mathrm{gg}}$ which can be found by solving (11) giving (12).

$$
t_{5}-t_{4}=-\mathrm{R}_{\mathrm{g}} \mathrm{C}_{\mathrm{iss}} \ln \left(\frac{\mathrm{V}_{\mathrm{mil}}-\mathrm{V}_{\mathrm{ggl}}}{\mathrm{V}_{\mathrm{gg}}-\mathrm{V}_{\mathrm{ggl}}}\right)
$$

Sub-period 2: $\left(t_{5}-t_{6}\right)$ (voltage rise time, $\left.t_{v r}\right)$

The state equations for this sub-period will be exactly the same as (A2). $t_{6}-t_{5}$ is the time required for $V_{a k}$ to reach zero from $\mathrm{V}_{\mathrm{dd}}$.

\section{Sub-period 3: $\left(t_{6}-t_{7}\right)$ (Current fall time, $\left.t_{i f}\right)$}

The state equations for this sub-period will be exactly the same as (A1). $t_{7}-t_{6}$ is the time required for $\mathrm{V}_{\mathrm{gs}}$ to reach $\mathrm{V}_{\text {th }}$ from $V_{g s}\left(t_{6}\right)$.

\section{Sub-period 4: $\left(t_{7}-t_{8}\right)$ (Ringing period)}

In this sub-period the MOSFET is in the cut-off region and the MOSFET output capacitor, $\mathrm{C}_{\text {oss }}$ resonates with the stray inductances of the circuit. So, the drain current can be expressed as (13). The state equations (A4) for this sub- 

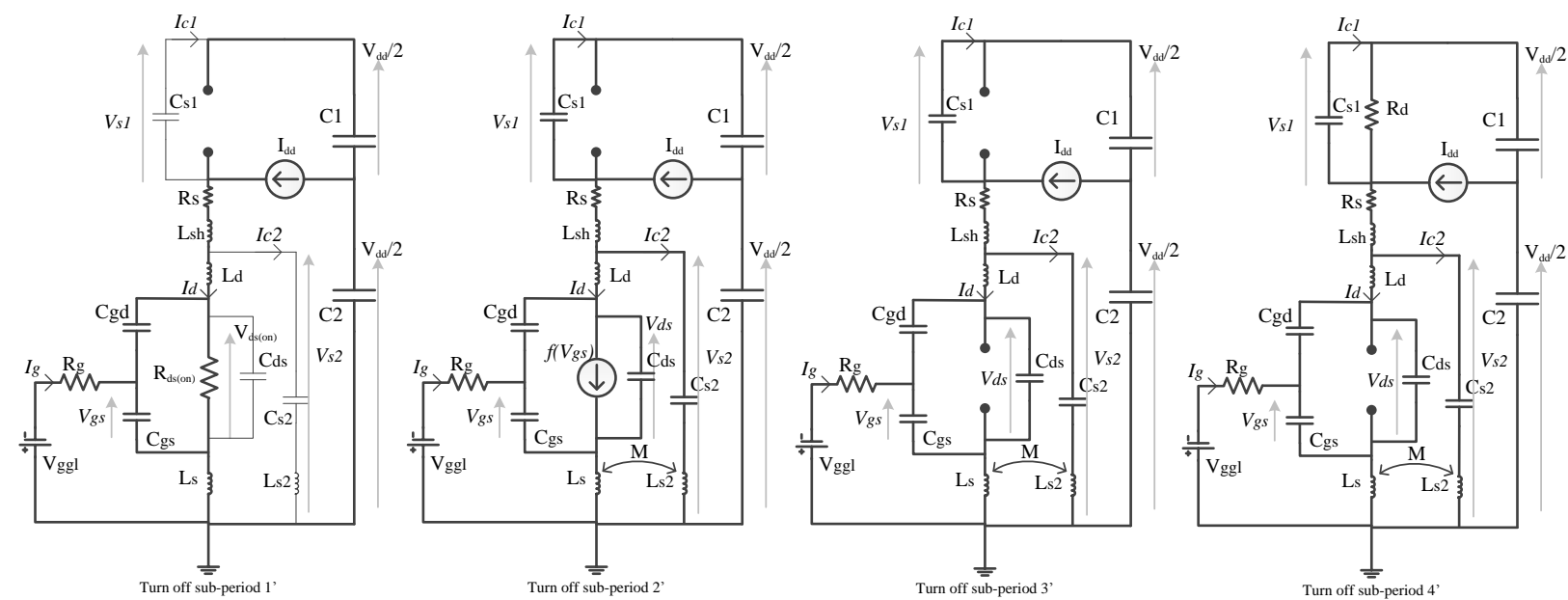

Fig. 7. Equivalent circuits for ZVS turn off stages of the lower device (DUT)

period are derived using (1)-(3), (6) and (13) and are shown in the Appendix.

$$
I_{d}(t)=\mathrm{C}_{\mathrm{oss}} \frac{d V_{d s}(t)}{d t}
$$

The time for this sub-period, $t_{8}-t_{7}$ is approximated by the time required for $V_{g s}$ to reach $\mathrm{V}_{\mathrm{ggl}}$ from $\mathrm{V}_{\mathrm{th}}$.

\section{B. Soft-switching}

To model the soft-switching transient for the $\mathrm{SiC}$ MOSFET only the turn off transient of the lower device (DUT) in Fig. 2(a) was modelled analytically because this transient also corresponds to turn on of the upper device. Parasitic components related to the upper device are neglected in the model to reduce the complexity. The validity of this assumption was confirmed by LTspice simulations. Similar to hard-switching, the soft-switching model is based on the solution of four equivalent circuits shown in Fig. 7, for the four distinct stages of the transient, (i) turn off delay, (ii) drain current fall, (iii) drain to source voltage rise and (iv) ringing periods. Two additional state variables, snubber capacitor current, $I_{c 2}$ and its rate of change, $\dot{I}_{c 2}$ were considered in addition to the other four state variables, $V_{g s}$, $V_{d s}, I_{d}$ and $\dot{I}_{d}$. The resulting state space equations are solved and the final value from a sub-period forms the initial condition for the next sub-period.

In Fig. 7, $\mathrm{L}_{\mathrm{d}}$ is the MOSFET drain lead inductance, $\mathrm{L}_{\mathrm{drain}}$. $\mathrm{L}_{\text {pcb }}$, $\mathrm{L}_{\text {lead }}$, and $\mathrm{L}_{\text {shunt }}$ are summed together in $\mathrm{L}_{\text {sh. }}$. The coupling factor, $\mathrm{k}$ between the snubber parasitic inductance, $\mathrm{L}_{\mathrm{s} 2}$ and MOSFET common source inductance, $\mathrm{L}_{\mathrm{s}}$ is approximated from (14)-(15). In the expression of mutual inductance, $\mathrm{M}(\mathrm{nH})$ between two parallel current conducting paths (14), $l_{\mathrm{a}}$ is the average length of the paths in $\mathrm{mm}$ and $\mathrm{d}$ is the distance between the paths in $\mathrm{mm}$ [14].

$$
\begin{aligned}
& \mathrm{M}=0.2 \mathrm{l}_{\mathrm{a}}\left(\ln \left(\frac{2 \mathrm{l}_{\mathrm{a}}}{\mathrm{d}}\right)-1+\frac{\mathrm{d}}{\mathrm{l}_{\mathrm{a}}}\right) \\
& \mathrm{k}=\frac{\mathrm{M}}{\sqrt{\mathrm{L}_{\mathrm{s} 2} \mathrm{~L}_{\mathrm{s}}}}
\end{aligned}
$$

\section{Sub-period 1': ( $t_{0}$ '- $t_{1}$ ') (turn off delay)}

Exactly same as the turn off delay sub-period of the hardswitching model (11)-(12).

\section{Sub-period 2': $\left(t_{1}{ }^{\prime}-t_{2}{ }^{\prime}\right)$ (Current fall period)}

The mutual inductance, $M$, between the snubber circuit parasitic inductor, $\mathrm{L}_{\mathrm{s} 2}$ and the common source inductor, $\mathrm{L}_{\mathrm{s}}$ is considered here when deriving the state equations. The system of state equations (A5) for this sub-period can be formed from (2)-(3), (7), and (16)-(20). Here, $V_{s 1}$ and $V_{s 2}$ are the voltages across the snubber capacitors. $t_{2}{ }^{\prime}-t_{1}$ ' is the time required for $V_{g s}$ to reach $\mathrm{V}_{\text {th }}$ from $\mathrm{V}_{\text {mil }}$.

$$
\begin{aligned}
& \mathrm{R}_{\mathrm{g}} I_{g}(t)= \mathrm{V}_{\mathrm{g}_{-} \text {in }}-V_{g s}(t)-\mathrm{L}_{\mathrm{s}} \frac{\mathrm{d} I_{d}(t)}{\mathrm{dt}}-\mathrm{M} \frac{\mathrm{d} I_{c 2}(t)}{\mathrm{dt}} \\
& V_{d s}(t)= \mathrm{V}_{\mathrm{dd}}-V_{s 1}(t)-\mathrm{R}_{\mathrm{s}}\left(I_{d}(t)+I_{c 2}(t)\right)-\mathrm{M} \frac{\mathrm{d} I_{c 2}(t)}{\mathrm{dt}} \\
& \quad-\left(\mathrm{L}_{\mathrm{s}}+\mathrm{L}_{\mathrm{d}}\right) \frac{\mathrm{d} I_{d}(t)}{\mathrm{dt}}-\mathrm{L}_{\mathrm{sh}} \frac{\mathrm{d}}{\mathrm{dt}}\left(I_{d}(t)+I_{c 2}(t)\right) \\
& \frac{d V_{s 1}(t)}{d t}= \frac{1}{\mathrm{C}_{\mathrm{s} 1}}\left(I_{d}(t)+I_{c 2}(t)-\mathrm{I}_{\mathrm{dd}}\right) \\
& \frac{d V_{s 2}(t)}{d t}= \mathrm{L}_{\mathrm{s} 2} \frac{\mathrm{d}^{2} I_{c 2}(t)}{\mathrm{dt}^{2}}+\frac{1}{\mathrm{C}_{\mathrm{s} 2}} I_{c 2}(t)+\mathrm{M} \frac{\mathrm{d}^{2} I_{d}(t)}{\mathrm{dt}^{2}} \\
& V_{s 1}(t)+ V_{s 2}(t)=\mathrm{V}_{\mathrm{dd}}-\mathrm{R}_{\mathrm{s}}\left(I_{d}(t)+I_{c 2}(t)\right)- \\
& \quad \mathrm{L}_{\mathrm{sh}} \frac{\mathrm{d}}{\mathrm{dt}}\left(I_{d}(t)+I_{c 2}(t)\right)
\end{aligned}
$$

\section{Sub-period 3': $\left(t_{2}{ }^{\prime}-t_{3}^{\prime}\right)$ (Voltage rise period)}

The state equations (A6) for this sub-period are derived using (2)-(3), (13), and (16)-(20). $t_{3}{ }^{\prime}-t_{2}{ }^{\prime}$ is the time required for $V_{s l}$ to reach zero from $V_{s l}\left(t_{2}{ }^{\prime}\right)$.

\section{Sub-period 4': ( $\left.t_{3}{ }^{\prime}-t_{4}{ }^{\prime}\right)$ (Ringing period)}

Because of the diode on state resistance, $R_{d}$, one additional state variable $V_{s l}$ has to be solved in this subperiod. The state equations (A7) are derived using (2)-(3), (13), (16)-(17), (19)-(20) and (21). $t_{4}{ }^{\prime}-t_{3}{ }^{\prime}$ is approximated by the time required for $V_{g s}$ to reach $\mathrm{V}_{\mathrm{ggl}}$ from $V_{g s}\left(t_{3}{ }^{\prime}\right)$.

$$
\frac{d V_{s 1}(t)}{d t}=\frac{1}{\mathrm{C}_{\mathrm{s} 1}}\left(I_{d}(t)+I_{c 2}(t)-\frac{V_{s 1}(t)}{\mathrm{R}_{\mathrm{d}}}-\mathrm{I}_{\mathrm{dd}}\right)
$$

\section{Analytical model implementation}

The analytical models were implemented in MATLAB using datasheet information of Cree $\mathrm{SiC}$ MOSFET, C2M0080120D, and different SiC Schottky diodes, C4D10120D and SCS230KE2. All other parameters including the power circuit parasitic values (measured using 
a precision impedance analyser, Agilent 4294A), MOSFET and Schottky diode package parasitic values (taken from respective datasheets and application notes) used for implementing the analytical model are shown in Table I. These values correspond to the experimental setup of the DPT.

TABLE I. PARAMETERS AND PARASITIC VALUES

\begin{tabular}{|c|c|c|c|c|}
\hline Section & Parameter & Value & Parameter & Value \\
\hline \multirow{6}{*}{ Power circuit } & $\mathrm{V}_{\mathrm{dd}}$ & $600 \mathrm{~V}$ & $\mathrm{I}_{\mathrm{dd}}$ & $8 \mathrm{~A}-25 \mathrm{~A}$ \\
\hline & $\mathrm{R}_{\text {shunt }}(\mathrm{DC})$ & $10 \mathrm{~m} \Omega$ & $\mathrm{L}_{\mathrm{pcb}}$ & $20 \mathrm{nH}$ \\
\hline & $\mathrm{R}_{\text {shunt }}(\mathrm{AC})$ & $53 \mathrm{~m} \Omega$ & Inductor, L & $462 \mu \mathrm{H}$ \\
\hline & $\mathrm{R}_{\mathrm{pcb}}(\mathrm{AC})$ & $100 \mathrm{~m} \Omega$ & $\mathrm{C}_{\mathrm{L}}(\mathrm{AC})$ & $6.5 \mathrm{pF}$ \\
\hline & \begin{tabular}{|l|}
$\mathrm{L}_{\text {shunt }}$ \\
\end{tabular} & $8 \mathrm{nH}$ & $\mathrm{R}_{\mathrm{L}}(\mathrm{AC})$ & $16.8 \Omega$ \\
\hline & $\mathrm{R}_{\text {leads }}(\mathrm{AC})$ & $70 \mathrm{~m} \Omega$ & & \\
\hline \multirow{2}{*}{$\begin{array}{c}\text { Gate drive } \\
\text { circuit }\end{array}$} & $\mathrm{V}_{\mathrm{gg}}$ & $20 \mathrm{~V}$ & $\mathrm{~V}_{\mathrm{ggl}}$ & $-4 \mathrm{~V}$ \\
\hline & $\mathrm{R}_{\mathrm{g}}$ & $11.27 \Omega$ & & \\
\hline \multirow{5}{*}{$\begin{array}{c}\text { SiC MOSFET } \\
\text { C2M0080120D }\end{array}$} & $\mathrm{R}_{\mathrm{ds}(\text { on })}\left(25^{\circ} \mathrm{C}\right)$ & $80 \mathrm{~m} \Omega$ & $\mathrm{g}_{\mathrm{m}}\left(25^{\circ} \mathrm{C}\right)$ & $8.1 \mathrm{~S}$ \\
\hline & $\mathrm{L}_{\mathrm{s}}$ & $10.5 \mathrm{nH}$ & $\mathrm{C}_{\text {iss_low voltage }}$ & $1500 \mathrm{pF}$ \\
\hline & $\mathrm{L}_{\text {drain }}$ & $7.5 \mathrm{nH}$ & $\mathrm{C}_{\text {iss_high voltage }}$ & $1100 \mathrm{pF}$ \\
\hline & $\mathrm{C}_{\mathrm{gd} \_ \text {low voltage }}$ & $370 \mathrm{pF}$ & $\mathrm{C}_{\text {oss_low voltage }}$ & $1000 \mathrm{pF}$ \\
\hline & $\mathrm{C}_{\mathrm{gd} \text { _high voltage }}$ & $7.5 \mathrm{pF}$ & $\mathrm{C}_{\text {oss_high voltage }}$ & $80 \mathrm{pF}$ \\
\hline \multirow{2}{*}{$\begin{array}{l}\text { Cree Diode, } \\
\text { C4D10120D }\end{array}$} & $\mathrm{L}_{\text {lead }}$ & $12.5 \mathrm{nH}$ & $\mathrm{R}_{\mathrm{d}}\left(25^{\circ} \mathrm{C}\right)$ & $55 \mathrm{~m} \Omega$ \\
\hline & $\mathrm{C}_{\text {ak_low voltage }}$ & $390 \mathrm{pF}$ & $\mathrm{C}_{\text {ak_high voltage }}$ & $20 \mathrm{pF}$ \\
\hline \multirow{2}{*}{$\begin{array}{l}\text { ROHM Diode, } \\
\text { SCS230KE2 }\end{array}$} & $\mathrm{L}_{\text {lead }}$ & $12.5 \mathrm{nH}$ & $\mathrm{R}_{\mathrm{d}}\left(25^{\circ} \mathrm{C}\right)$ & $15 \mathrm{~m} \Omega$ \\
\hline & $\mathrm{C}_{\mathrm{ak} \_ \text {low voltage }}$ & $790 \mathrm{pF}$ & $\mathrm{C}_{\mathrm{ak} \_ \text {high voltage }}$ & $63 \mathrm{pF}$ \\
\hline \multirow{2}{*}{ Snubber circuit } & $\mathrm{C}_{\mathrm{s} 1}, \mathrm{C}_{\mathrm{s} 2}$ & $1 \mathrm{nF}$ & $\mathrm{L}_{\mathrm{s} 2}$ & $2 \mathrm{nH}$ \\
\hline & $\mathrm{k}$ & 0.95 & & \\
\hline
\end{tabular}

The stray resistance of the power loop, $R_{s}$ is the sum of the resistances of current shunt resistor, $\mathrm{R}_{\text {shunt }}, \mathrm{PCB}$ current paths, $\mathrm{R}_{\mathrm{PCB}}$, MOSFET and diode resistors $\left(\mathrm{R}_{\mathrm{ds}(\mathrm{on})}\right), \mathrm{R}_{\mathrm{d}}$ and $\left.\mathrm{R}_{\text {leads }}\right)$. The inter-winding parasitic capacitance of the load inductor, $\mathrm{C}_{\mathrm{L}}$ and its high frequency $\mathrm{AC}$ resistance, $\mathrm{R}_{\mathrm{L}}$ are also included in the model in the appropriate sub-periods.

\section{SIMULATION AND EXPERIMENTAL RESULTS OF HARD- SWITCHING}

A $600 \mathrm{~V}, 25 \mathrm{~A}$ double-pulse test (DPT) circuit shown in Fig. 8 was designed to examine the switching characteristics of second generation Cree C2M0080120D SiC MOSFETs. Cree SiC MOSFET gate driver circuit, CRD-001 was used to drive the MOSFETs. T\&M Research's high-bandwidth current shunt resistor, SDN-414-01 was used to accurately measure the drain / source current. The connection of the load inductor can be changed to enable both hard-switching and soft-switching tests to be performed using the same circuit for fair comparison.

The DPT circuits were also simulated in LTspice using the SPICE models of the SiC MOSFET and Schottky diodes. A time step of $0.01 \mathrm{~ns}$ was selected for both the analytical model implementation and the LTspice simulation as SiC MOSFET switching transient times are of tens of ns. Experimental, analytical and LTspice simulation hardswitching transients for $600 \mathrm{~V} 20 \mathrm{~A}$ and $600 \mathrm{~V} 13 \mathrm{~A}$ DPT operation are shown in Fig. 9-12 for two different Schottky diodes. The $V_{d s}$ and $V_{g s}$ waveforms include the voltages across the device package inductances. Switching losses from different experiments are summarised in Table II. It is evident that compared to the LTspice models the analytical models gave a better switching loss estimation. The maximum error from analytical models was around $6 \%$ with respect to the experimental results (experiments with the
ROHM diode). However, the individual turn on and turn off loss estimation for the 20A experiments was worse in analytical modelling than LTspice. The reason may be the better incorporation of the nonlinearity in device junction capacitances in the LTspice model which enabled better approximation of voltage and current transitions in $20 \mathrm{~A}$ experiments shown in Fig. 9-10.

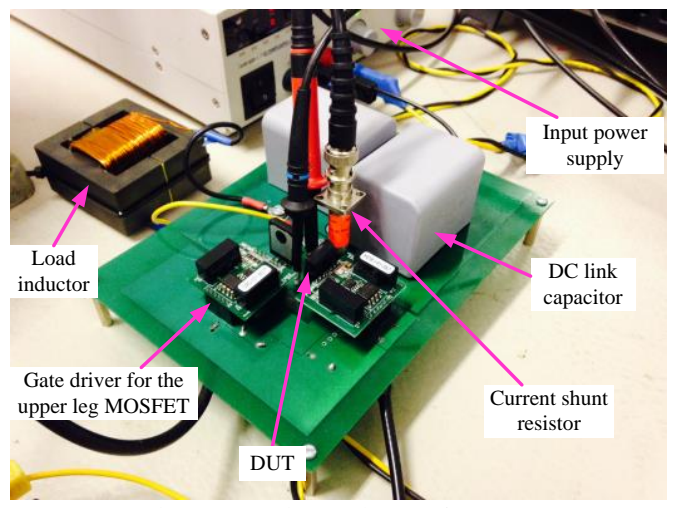

Fig. 8. Experimental setup for DPT tests

Also the Cree diode SPICE model gives better simulation results than the ROHM diode SPICE model. The maximum error in switching loss estimation was around $16 \%$ and $29 \%$ from simulations with Cree diode and ROHM diode SPICE models, respectively. However, both experimental and LTspice turn off losses include the energy stored in the device output capacitance and other circuit stray capacitances, which eventually is dissipated during the turn on transient. The analytical model gives a way for calculating the actual turn on and turn off losses from the modelled channel current of the MOSFET and $V_{d s}$.

The advantage of the proposed analytical model over the LTspice model is a 3 times reduction in simulation time, a single turn on transient takes $0.6 \mathrm{~s}$ to complete on an Intel Core i7 $3.4 \mathrm{GHz}$ computer, and better incorporation of the high frequency parasitic components such as incorporation of the $\mathrm{AC}$ resistance of the load inductor during the turn on ringing stage, sub-period 4 . Also the effect of temperature on the switching transients can be evaluated easily by changing the temperature dependent parameters in Table I. However, the modelling of ringing in the different waveforms is still limited in both the analytical and LTspice models. Additional parasitic elements such as drain to gate external parasitic capacitance may need to be considered for better modelling of ringing.

TABLE II. SWITCHING LOSS COMPARISON

\begin{tabular}{|c|c|c|c|c|}
\hline \multirow{2}{*}{ Conditions } & \multirow{2}{*}{ State } & \multicolumn{3}{|c|}{ Loss $(\boldsymbol{\mu J})$} \\
\cline { 3 - 5 } & & Analytical & Experiment & LTspice \\
\hline 600V 20A & Turn on & 171 & 235 & 228 \\
\cline { 2 - 5 } with Cree & Turn off & 149 & 74 & 129 \\
\cline { 2 - 5 } C4D10120D & Total & 320 & 309 & 357 \\
\hline 600V 20A & Turn on & 207 & 263 & 302 \\
\cline { 2 - 5 } with ROHM & Turn off & 150 & 75 & 104 \\
\cline { 2 - 5 } SCS230KE2 & Total & 357 & 338 & 406 \\
\hline 600V 13A & Turn on & 92 & 111 & 128 \\
\cline { 2 - 5 } with Cree & Turn off & 69 & 54 & 59 \\
C4D10120D & Total & 161 & 165 & 187 \\
\hline 600V 13A & Turn on & 118 & 118 & 199 \\
\cline { 2 - 5 } with ROHM & Turn off & 64 & 75 & 49 \\
\cline { 2 - 5 } SCS230KE2 & Total & 182 & 193 & 248 \\
\hline
\end{tabular}




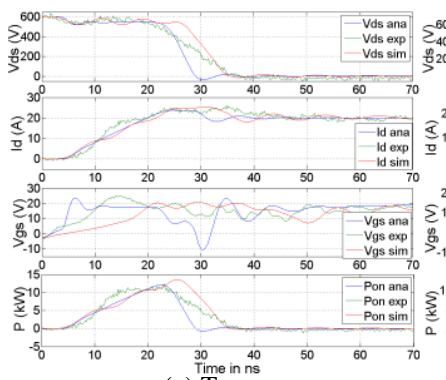

(a) T'urn on

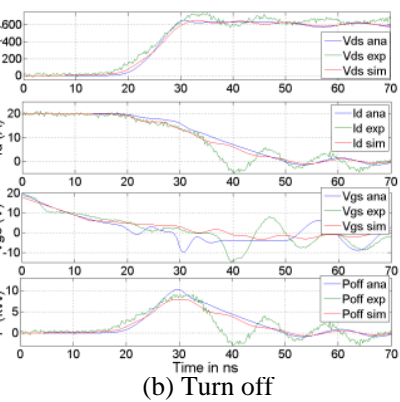

(b) Turn oft
Fig. 9. 600V, 20A results with Cree C4D10120D diode

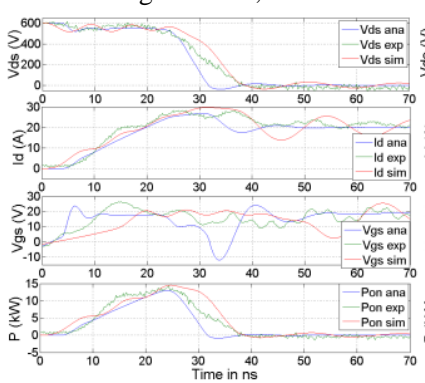

(a) Turn on

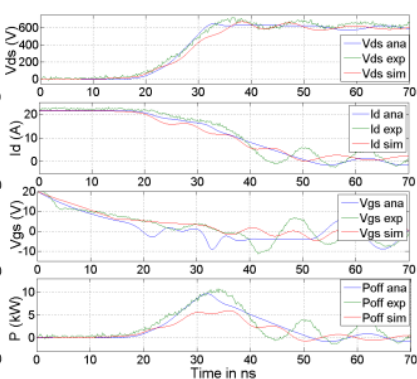

(b) Turn off
Fig. 10. 600V, 20A results with ROHM SCS230KE2 diode

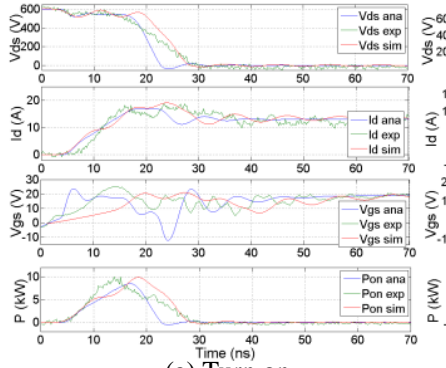

(a) Turn on

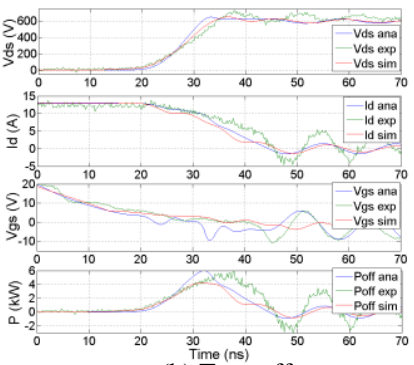

(b) Turn off
Fig. 11. 600V, 13A results with Cree C4D10120D diode

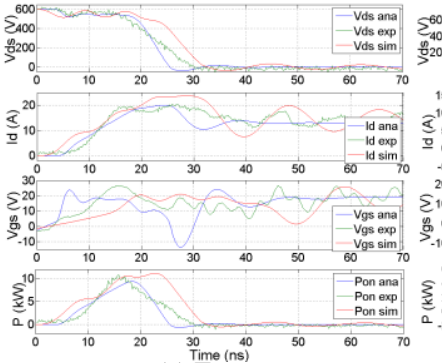

(a) Turn on

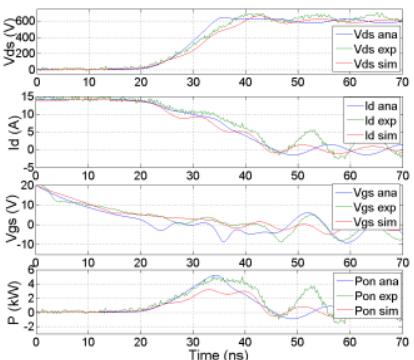

(b) Turn off
Fig. 12. 600V, 13A results with ROHM SCS230KE2 diode

\section{SIMULATION AND EXPERIMENTAL RESULTS OF SOFT- SWITCHING}

The DPT circuit was tested in the soft-switching configuration for different current and voltage levels using the same Cree MOSFET as used in the hard-switching tests as the upper and lower leg devices. To change the coupling between the snubber branch and MOSFET common source inductance, snubber capacitors were place in parallel (close to DUT) or perpendicular (away from DUT) to the device current path. With the perpendicular arrangement the coupling factor, k was assumed to be zero. Fig. 13 and Fig.
14 show experimental, analytical and simulation results of soft-switching at 600V, 25A and 13A. Comparing Fig. 14 (a) with Fig. 11(b), the snubber circuit has reduced both the $\mathrm{dv} / \mathrm{dt}$ by a factor of eight and the frequency of oscillations by a factor of three. The effect of mutual coupling between the snubber branch and MOSFET common source inductance is also evident in the $V_{g s}$ waveforms in Fig. 13 and Fig. 14. Both snubber current and $V_{g s}$ have the same oscillation frequency and the oscillation in $V_{g s}$ is dependent on the coupling factor between the two parasitic inductances.

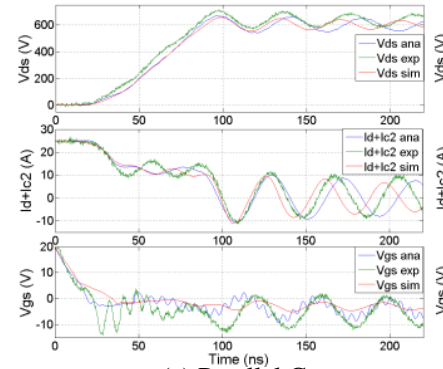

(a) Parallel $\mathrm{C}$

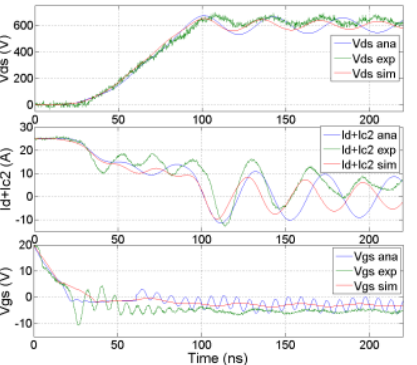

(b) Perpendicular $\mathrm{C}_{\mathrm{s}}$
Fig. 13. 600V, 25A DPT results for ZVS at turn off

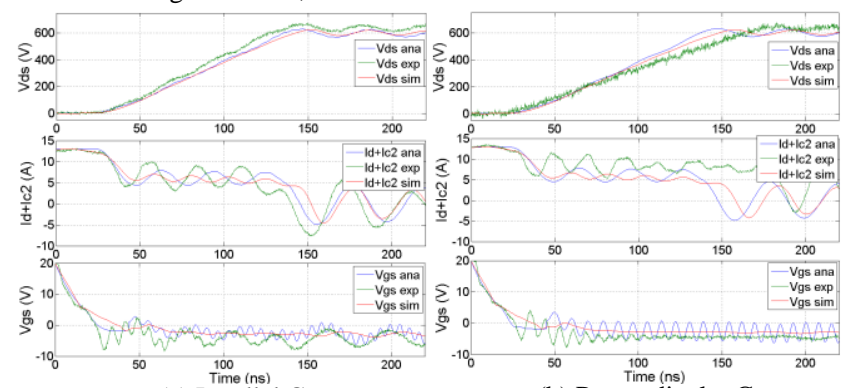

(a) Parallel $C_{s}$

(b) Perpendicular $\mathrm{C}_{\mathrm{s}}$

Fig. 14. 600V, 13A DPT results for ZVS at turn off

The analytical model also enables the calculation of the small turn off loss of $29 \mu \mathrm{J}$ and $4 \mu \mathrm{J}$ for $25 \mathrm{~A}$ and $13 \mathrm{~A}$ operations, respectively by separating the MOSFET drain current, $I_{d}$, from the shunt resistor current, $I_{d}+I_{c 2}$. Turn on losses will be approximately zero as the MOSFET turns on with zero voltage across it because of its body diode conduction. Therefore, for 13A ZVS operation around 93\% of the hard-switching energy was saved during turn off making the total soft-switching loss reduction $98 \%$ compared to the hard-switching operation.

\section{CONCLUSIONS}

The analytical model presented in the paper, and validated experimentally can be used to enable rapid and accurate evaluation of circuit waveforms and device switching losses. The analytical model uses only datasheet parameters, so the impact on circuit operation and switching losses of SiC MOSFETs or diodes with different snubber capacitor values and circuit parasitics can be evaluated.

The paper also describes the analytical and experimental evaluation of the impact of soft-switching techniques on the MOSFET switching loss, dv/dt and parasitic ringing due to the introduction of additional parasitic inductance, which provides an understanding of the benefits of soft-switching in 
very high speed $\mathrm{SiC}$ circuits and identifies the key parasitic elements which limit performance. Switching loss was reduced by $98 \%$ in the soft-switching operation along with the reduced oscillations (33\%) in different circuit waveforms compared to hard-switching operation. Also the $88 \%$ reduction in $\mathrm{dv} / \mathrm{dt}$ during the switching transients can significantly reduce the EMI signature of the soft-switching circuit. These improvements suggest the use of softswitching techniques in high speed SiC MOSFET based converters could offer significant performance benefits.

\section{APPENDIX}

$\left[\begin{array}{c}\dot{V}_{g s} \\ \dot{V}_{d s} \\ \dot{I}_{d} \\ \dot{I}_{d}\end{array}\right]=\left[\begin{array}{cccc}-(\mathrm{a} 1+\mathrm{a} 2) & \mathrm{a} 3 & \mathrm{a} 4 & 0 \\ -\mathrm{b} 1 & 0 & \mathrm{~b} 2 & 0 \\ 0 & 0 & 0 & 1 \\ \mathrm{~d} 1 & 0 & -\mathrm{d} 2 & -\mathrm{d} 3\end{array}\right]\left[\begin{array}{c}V_{g s} \\ V_{d s} \\ I_{d} \\ \dot{I}_{d}\end{array}\right]+\left[\begin{array}{c}\mathrm{u} 1+\mathrm{u} 2+\mathrm{u} 3 \\ \mathrm{v} 1 \\ 0 \\ -\mathrm{w} 1\end{array}\right]$

$\left[\begin{array}{c}\dot{V}_{g s} \\ \dot{V}_{d s} \\ \dot{I}_{d} \\ \dot{I}_{d}\end{array}\right]=\left[\begin{array}{cccc}-(\mathrm{a} 1+\mathrm{a} 2) & 0 & \mathrm{a} 4 & -\mathrm{a} 5 \\ -\mathrm{b} 1 & 0 & \mathrm{~b} 2 & 0 \\ 0 & 0 & 0 & 1 \\ \mathrm{~d} 1 & 0 & -\mathrm{d} 4 & -\mathrm{d} 3\end{array}\right]\left[\begin{array}{c}V_{g s} \\ V_{d s} \\ I_{d} \\ \dot{I}_{d}\end{array}\right]+\left[\begin{array}{c}\mathrm{u} 1+\mathrm{u} 2 \\ \mathrm{v} 1 \\ 0 \\ \mathrm{w} 2-\mathrm{w} 1\end{array}\right]$

$\left[\begin{array}{c}\dot{V}_{g s} \\ \dot{I}_{d} \\ \dot{I}_{d}\end{array}\right]=\left[\begin{array}{ccc}-\mathrm{a} 1 & 0 & -\mathrm{a} 5 \\ 0 & 0 & 1 \\ 0 & -\mathrm{d} 5 & -\mathrm{d} 3\end{array}\right]\left[\begin{array}{c}V_{g s} \\ I_{d} \\ \dot{I}_{d}\end{array}\right]+\left[\begin{array}{c}\mathrm{u} 1 \\ 0 \\ \mathrm{w} 2\end{array}\right]$

$\left[\begin{array}{c}\dot{V}_{g s} \\ \dot{V}_{d s} \\ \dot{I}_{d} \\ \dot{I}_{d}\end{array}\right]=\left[\begin{array}{cccc}-\mathrm{a} 1 & 0 & \mathrm{a} 4 & -\mathrm{a} 5 \\ 0 & 0 & \mathrm{~b} 2 & 0 \\ 0 & 0 & 0 & 1 \\ 0 & 0 & -\mathrm{d} 2 & -\mathrm{d} 3\end{array}\right]\left[\begin{array}{c}V_{g s} \\ V_{d s} \\ I_{d} \\ \dot{I}_{d}\end{array}\right]+\left[\begin{array}{c}\mathrm{u} 1 \\ 0 \\ 0 \\ 0\end{array}\right]$

$\left[\begin{array}{c}\dot{V}_{g s} \\ \dot{V}_{d s} \\ \dot{I}_{d} \\ \dot{I}_{d} \\ \dot{I}_{c 2} \\ \dot{I}_{c 2}\end{array}\right]=\left[\begin{array}{cccccc}-(\mathrm{a} 1+\mathrm{a} 2) & 0 & \mathrm{a} 4 & -\mathrm{a} 5 & 0 & -\mathrm{a} 6 \\ -\mathrm{b} 1 & 0 & \mathrm{~b} 2 & 0 & 0 & 0 \\ 0 & 0 & 0 & 1 & 0 & 0 \\ \mathrm{e} 1 & 0 & \mathrm{e} 2 & \mathrm{e} 3 & \mathrm{e} 4 & e 5 \\ 0 & 0 & 0 & 0 & 0 & 1 \\ \mathrm{f} 1 & 0 & \mathrm{f} 2 & \mathrm{f} 3 & \mathrm{f} 4 & \mathrm{f} 5\end{array}\right]\left[\begin{array}{c}V_{g s} \\ V_{d s} \\ I_{d} \\ \dot{I}_{d} \\ I_{c 2} \\ \dot{I}_{c 2}\end{array}\right]+\left[\begin{array}{c}\mathrm{u} 1+\mathrm{u} 2 \\ \mathrm{v} 1 \\ 0 \\ \mathrm{x} 1-\mathrm{x} 2 \\ 0 \\ \mathrm{y} 1-\mathrm{y} 2\end{array}\right]$ (A5)

$\left[\begin{array}{c}\dot{V}_{g s} \\ \dot{V}_{d s} \\ \dot{I}_{d} \\ \dot{I}_{d} \\ \dot{I}_{c 2} \\ \dot{I}_{c 2}\end{array}\right]=\left[\begin{array}{cccccc}-\mathrm{a} 1 & 0 & \mathrm{a} 4 & -\mathrm{a} 5 & 0 & -\mathrm{a} 6 \\ 0 & 0 & \mathrm{~b} 2 & 0 & 0 & 0 \\ 0 & 0 & 0 & 1 & 0 & 0 \\ 0 & 0 & \mathrm{e} 2 & \mathrm{e} 3 & \mathrm{e} 4 & \mathrm{e} 5 \\ 0 & 0 & 0 & 0 & 0 & 1 \\ 0 & 0 & \mathrm{f} 2 & \mathrm{f} 3 & \mathrm{f} 4 & \mathrm{f} 5\end{array}\right]\left[\begin{array}{c}V_{g s} \\ V_{d s} \\ I_{d} \\ \dot{I}_{d} \\ I_{c 2} \\ \dot{I}_{c 2}\end{array}\right]+\left[\begin{array}{c}\mathrm{u} 1 \\ 0 \\ 0 \\ \mathrm{x} 1 \\ 0 \\ \mathrm{y} 1\end{array}\right]$

$\left[\begin{array}{c}\dot{V}_{g s} \\ \dot{V}_{d s} \\ \dot{I}_{d} \\ \dot{I}_{d} \\ \dot{I}_{c 2} \\ \dot{I}_{c 2} \\ \dot{V}_{s 1}\end{array}\right]=\left[\begin{array}{ccccccc}-\mathrm{a} 1 & 0 & \mathrm{a} 4 & -\mathrm{a} 5 & 0 & -\mathrm{a} 6 & 0 \\ 0 & 0 & \mathrm{~b} 2 & 0 & 0 & 0 & 0 \\ 0 & 0 & 0 & 1 & 0 & 0 & 0 \\ 0 & 0 & \mathrm{e} 2 & \mathrm{e} 3 & \mathrm{e} 4 & \mathrm{e} 5 & \mathrm{e} 6 \\ 0 & 0 & 0 & 0 & 0 & 1 & 0 \\ 0 & 0 & \mathrm{f} 2 & \mathrm{f} 3 & \mathrm{f} 4 & \mathrm{f} 5 & \mathrm{f} 6 \\ 0 & 0 & \mathrm{~g} 1 & 0 & \mathrm{~g} 1 & 0 & -\mathrm{g} 2\end{array}\right]\left[\begin{array}{c}V_{g s} \\ V_{d s} \\ I_{d} \\ \dot{I}_{d} \\ I_{c 2} \\ \dot{I}_{c 2} \\ V_{s 1}\end{array}\right]+\left[\begin{array}{c}\mathrm{u} 1 \\ 0 \\ 0 \\ \mathrm{x} 1 \\ 0 \\ \mathrm{y} 1 \\ -z 1\end{array}\right]$

$$
\begin{gathered}
\mathrm{a} 1=\frac{1}{\mathrm{Rg}_{\mathrm{g}}} \\
\mathrm{a} 2=\frac{\mathrm{g}_{\mathrm{m}} \mathrm{Cgd}_{\mathrm{gd}}}{\mathrm{C}_{\mathrm{iss}} \mathrm{C}_{\text {oss }}} \\
\mathrm{a} 3=\frac{\mathrm{L}_{\mathrm{s}}}{\mathrm{Rg}_{\mathrm{g}} \mathrm{C}_{\mathrm{iss}}\left(\mathrm{L}_{\mathrm{s}}+\mathrm{L}_{\mathrm{d}}\right)} \\
\mathrm{a} 4=\frac{\mathrm{C}_{\mathrm{gd}}}{\mathrm{C}_{\mathrm{iss}} \mathrm{C}_{\text {oss }}} \\
\mathrm{a} 5=\frac{\mathrm{L}_{\mathrm{s}}}{\mathrm{Rg}_{\mathrm{g}} \mathrm{C}_{\text {iss }}} \\
\mathrm{a} 6=\frac{\mathrm{M}}{\mathrm{R}_{\mathrm{g}} \mathrm{C}_{\text {iss }}} \\
\mathrm{b} 1=\frac{\mathrm{gm}_{\mathrm{m}}}{\mathrm{C}_{\text {oss }}}
\end{gathered}
$$

$$
\begin{aligned}
& \begin{array}{c}
\mathrm{b} 2=\frac{1}{\mathrm{C}_{\text {oss }}} \\
\mathrm{d} 1=\frac{\left.\mathrm{gm}_{\mathrm{m}}+\mathrm{L}_{\mathrm{d}}\right)}{\mathrm{C}_{\mathrm{oss}}\left(\mathrm{L}_{\mathrm{s}}+\mathrm{L}_{\mathrm{d}}\right.}
\end{array} \\
& \mathrm{d} 2=\frac{1}{\mathrm{C}_{\text {oss }}\left(\mathrm{L}_{\mathrm{s}}+\mathrm{L}_{\mathrm{d}}\right)} \\
& \mathrm{d} 3=\frac{\mathrm{R}_{\mathrm{s}}}{\mathrm{L}_{\mathrm{s}}+\mathrm{L}_{\mathrm{d}}} \\
& \mathrm{d} 4=\frac{\mathrm{C}_{\mathrm{ak}}+\mathrm{C}_{\text {oss }}}{\mathrm{C}_{\mathrm{ak}} \mathrm{C}_{\mathrm{oss}}\left(\mathrm{L}_{\mathrm{s}}+\mathrm{L}_{\mathrm{d}}\right)} \\
& \mathrm{d} 5=\frac{1}{\mathrm{C}_{\mathrm{ak}}\left(\mathrm{L}_{\mathrm{s}}+\mathrm{L}_{\mathrm{d}}\right)} \\
& \text { Where, } \mathrm{L}_{\mathrm{e} 1}=\frac{\mathrm{L}_{\mathrm{sh}}+\mathrm{M}}{\mathrm{M}^{2}+2 \mathrm{~L}_{\mathrm{sh}} \mathrm{M}-\mathrm{L}_{\mathrm{sh}}\left(\mathrm{L}_{\mathrm{s}}+\mathrm{L}_{\mathrm{d}}\right)-\mathrm{L}_{\mathrm{s} 2}\left(\mathrm{~L}_{\mathrm{s}}+\mathrm{L}_{\mathrm{d}}\right)-\mathrm{L}_{\mathrm{s} 2} \mathrm{~L}_{\mathrm{sh}}} \\
& L_{e 2}=\frac{M^{2}+2 L_{s h} M-L_{s h}\left(L_{s}+L_{d}\right)-L_{s 2}\left(L_{s}+L_{d}\right)-L_{s 2} L_{s h}}{M^{2}+2 L_{s h} M-L_{s h}\left(L_{s}+L_{d}+L_{d}\right)-L_{s 2}\left(L_{s}+L_{d}\right)-L_{s 2} L_{s h}} \\
& \mathrm{~L}_{\mathrm{e} 3}=-\frac{\mathrm{L}_{\mathrm{sh}}+\mathrm{L}_{\mathrm{s} 2}}{\mathrm{M}^{2}+2 \mathrm{~L}_{\mathrm{sh}} \mathrm{M}-\mathrm{L}_{\mathrm{sh}}\left(\mathrm{L}_{\mathrm{s}}+\mathrm{L}_{\mathrm{d}}\right)-\mathrm{L}_{\mathrm{s} 2}\left(\mathrm{~L}_{\mathrm{s}}+\mathrm{L}_{\mathrm{d}}\right)-\mathrm{L}_{\mathrm{s} 2} \mathrm{~L}_{\mathrm{sh}}} \\
& \mathrm{L}_{\mathrm{e} 4}=-\frac{\mathrm{L}_{\mathrm{sh}}+\mathrm{M}}{\mathrm{M}^{2}+2 \mathrm{~L}_{\mathrm{sh}} \mathrm{M}-\mathrm{L}_{\mathrm{sh}}\left(\mathrm{L}_{\mathrm{s}}+\mathrm{L}_{\mathrm{d}}\right)-\mathrm{L}_{\mathrm{s} 2}\left(\mathrm{~L}_{\mathrm{s}}+\mathrm{L}_{\mathrm{d}}\right)-\mathrm{L}_{\mathrm{s} 2} \mathrm{~L}_{\mathrm{sh}}} \\
& \begin{array}{c}
\mathrm{x} 2=\frac{\mathrm{L}_{\mathrm{e} 3} \mathrm{~g}_{\mathrm{m}} \mathrm{V}_{\mathrm{th}}}{\mathrm{C}_{\mathrm{oss}}} \\
\mathrm{y} 1=\frac{\mathrm{I}_{\mathrm{dd}}\left(\mathrm{L}_{\mathrm{e} 1}-\mathrm{L}_{\mathrm{e} 2}\right)}{\mathrm{C}_{\mathrm{s} 1}} \\
\mathrm{y} 2=\frac{\mathrm{L}_{\mathrm{e} 1} \mathrm{~g}_{\mathrm{m}} \mathrm{V}_{\mathrm{th}}}{\mathrm{C}_{\mathrm{oss}}} \\
\mathrm{z} 1=\frac{\mathrm{I}_{\mathrm{dd}}}{\mathrm{C}_{\mathrm{s} 1}}
\end{array} \\
& \mathrm{~g} 2=\frac{1}{\mathrm{C}_{\mathrm{s} 1} \mathrm{R}_{\mathrm{d}}}
\end{aligned}
$$

\section{REFERENCES}

[1] T. Kimoto, and J. A. Cooper, Fundamentals of Silicon Carbide Technology: Growth, Characterization, Devices and Applications: John Wiley \& Sons, 2014.

[2] N. Mohan, and T. M. Undeland, Power electronics: converters, applications, and design: John Wiley \& Sons, 2007.

[3] M. Mudholkar, S. Ahmed, M. N. Ericson et al., "Datasheet Driven Silicon Carbide Power MOSFET Model," IEEE Transactions on Power Electronics, vol. 29, no. 5, pp. 2220-2228, 2014.

[4] S. Potbhare, N. Goldsman, A. Akturk et al., "Energy- and TimeDependent Dynamics of Trap Occupation in $4 \mathrm{H}-\mathrm{SiC}$ MOSFETs," IEEE Transactions on Electron Devices, vol. 55, no. 8, pp. 20612070, 2008.

[5] C. Zheng, D. Boroyevich, R. Burgos et al., "Characterization and modeling of $1.2 \mathrm{kv}, 20 \mathrm{~A}$ SiC MOSFETs," IEEE Energy Conversion Congress and Exposition (ECCE), pp. 1480-1487, 20-24 Sept. 2009.

[6] W. Jun, Z. Tiefu, L. Jun et al., "Characterization, Modeling, and Application of 10-kV SiC MOSFET," IEEE Transactions on Electron Devices, vol. 55, no. 8, pp. 1798-1806, 2008.

[7] J. Fabre, P. Ladoux, and M. Piton, "Characterization and Implementation of Dual-SiC MOSFET Modules for future use in Traction Converters," IEEE Transactions on Power Electronics, vol. 30, no. 8, pp. 4079-4090, 2015.

[8] R. Khanna, A. Amrhein, W. Stanchina et al., "An analytical model for evaluating the influence of device parasitics on Cdv/dt induced false turn-on in SiC MOSFETs," Twenty-Eighth Annual IEEE Applied Power Electronics Conference and Exposition (APEC) pp. 518-525, 17-21 March 2013.

[9] C. DiMarino, C. Zheng, M. Danilovic et al., "High-temperature characterization and comparison of $1.2 \mathrm{kV} \mathrm{SiC}$ power MOSFETs," IEEE Energy Conversion Congress and Exposition (ECCE), pp. 3235-3242, 15-19 Sept. 2013.

[10] G. Calderon-Lopez, and A. J. Forsyth, "High power density DC-DC converter with $\mathrm{SiC}$ MOSFETs for electric vehicles," 7th IET International Conference on Power Electronics, Machines and Drives (PEMD), pp. 1-6, 8-10 April 2014.

[11] M. R. Ahmed, G. Calderon-Lopez, F. Bryan et al., "Soft-Switching $\mathrm{SiC}$ Interleaved Boost Converter," IEEE Applied Power Electronics Conference and Exposition (APEC), pp. 941-947, 15-19 March 2015.

[12] R. Yuancheng, X. Ming, J. Zhou et al., "Analytical loss model of power MOSFET," IEEE Transactions on Power Electronics, vol. 21, no. 2, pp. 310-319, 2006.

[13] W. Jianjing, H. S. H. Chung, and R. T. H. Li, "Characterization and Experimental Assessment of the Effects of Parasitic Elements on the MOSFET Switching Performance," IEEE Transactions on Power Electronics, vol. 28, no. 1, pp. 573-590, 2013.

[14] E. B. Rosa, "The Self and Mutual Inductances of Linear Conductors," Bulletin of the Bureau of Standards, vol. 4, no. 2, 1908. 